\title{
Using the Glasgow Benefit Inventory questionnaire to quantify the health benefits of lymphoedema treatment in patients with head and neck cancer
}

\author{
Edwin Halliday ${ }^{1 *}$ (D), Jayne Gittins ${ }^{2}$ and Syed Farhan Ahsan ${ }^{1}$
}

\begin{abstract}
Background: Lymphoedema is a common side effect after treatment for head and neck cancer. Our treatment protocol involves staging the degree of lymphoedema and then offering treatment comprising skin care, manual lymphatic drainage, simple lymphatic drainage, compression and elastic therapeutic tape. The Glasgow Benefit Inventory is a validated post-interventional questionnaire applicable to otorhinolaryngology interventions which measures changes in health status. The aim of this study was to quantify the health benefits of lymphoedema treatment using the Glasgow Inventory Benefit questionnaire, in patients with a history of treated head and neck cancer.
\end{abstract}

Methods: Any patient who had undergone treatment with curative intent of a primary head and neck malignancy who had been referred for lymphoedema treatment within a 6 month period was eligible for inclusion. Patients completed a questionnaire after finishing the course of lymphoedema treatment.

Results: A total of 15 patients completed the questionnaire. Ten patients (67\%) demonstrated some level of improvement in quality of life, while two (13\%) reported no benefit and three (20\%) reported negative improvements. The average score for the total Glasgow Benefit Inventory scale was + 7.2. The greatest benefit was demonstrated with the physical benefit subscale $(+13.1)$. The average general benefit score was +9.0 .

Conclusions: Lymphoedema treatment involves techniques which can fairly easily be taught to patients to complete at home. In this study, there were mild improvements in patient reported quality of life using the Glasgow Benefit Inventory in the majority of patients. Clinical interest has increased in lymphoedema recently, but there is still limited information about the effectiveness of treatments and future research should look to address these issues.

Keywords: Glasgow Benefit Inventory, Head and neck neoplasms, Lymphedema, Quality of life

\section{Background}

The morbidity associated with the treatment of head and neck cancer can be significant and most patients will have some side effects during treatment and for several weeks afterwards. Some side effects may become

\footnotetext{
* Correspondence: edwin.halliday@gmail.com

'Department of ENT, Shrewsbury and Telford Hospital NHS Trust, Royal

Shrewsbury Hospital, Mytton Oak Road, Shrewsbury SY3 8XQ, UK

Full list of author information is available at the end of the article
}

long-term and indeed others may develop months or even years after treatment. Lymphoedema is one of the side effects after treatment and can present with swelling to the neck, particularly in the submental area. It has been estimated that lymphoedema may affect up to $50 \%$ of patients treated for head and neck cancer $[1,2]$. Risk factors for lymphoedema include the location of the tumour, time since the end of treatment, total dosage

(c) The Author(s). 2020 Open Access This article is licensed under a Creative Commons Attribution 4.0 International License, which permits use, sharing, adaptation, distribution and reproduction in any medium or format, as long as you give

appropriate credit to the original author(s) and the source, provide a link to the Creative Commons licence, and indicate if changes were made. The images or other third party material in this article are included in the article's Creative Commons licence, unless indicated otherwise in a credit line to the material. If material is not included in the article's Creative Commons licence and your intended use is not permitted by statutory regulation or exceeds the permitted use, you will need to obtain permission directly from the copyright holder. To view a copy of this licence, visit http://creativecommons.org/licenses/by/4.0/. 
and days of radiation therapy, radiation status of surgical bed and number of treatment modalities [3].

Lymphoedema results when the lymphatic load exceeds the transport capacity of the lymphatic system and may be primary or secondary [4]. In secondary lymphoedema, there is inadequate drainage of the high protein lymphatic fluid caused by radiotherapy or surgery which may remove lymph nodes entirely or disrupt lymphatic flow. This results in overload of lymphatic fluid within the interstitial tissues which often produces internal and external oedema $[5,6]$. This can have both cosmetic and functional consequences, including impairment in communication, swallowing and breathing [7]. It is important also to acknowledge that psychosocial distress is often a major symptom accompanying treatment for head and neck cancers, particularly if lymphoedema develops $[6,8]$.

Management of head and neck lymphoedema is often based on reasonable clinical judgement as there are a lack of randomised controlled trials producing evidencebased treatments [6]. Therefore, subjective assessment by a lymphoedema practitioner is used to ascertain the degree of oedema, any skin changes, tissue quality and range of movement of the cervical spine [9]. The subjective staging of the oedema can be based on staging systems such as those devised by Foldi [10] and the International Society of Lymphology [11], although it is acknowledged that these all have limitations when used to categorise lymphoedema. In recent years, the aim is to encourage self-care of lymphoedema which is key to successful maintenance and management of this chronic condition $[9,12]$.

In our department, as part of the routine care following head and neck cancer treatment, patients who have developed lymphoedema and who would like to consider treatment are offered referral to a lymphoedema team based at the local hospice. The hospice lymphoedema service protocol for treatment of patients with head and neck cancer related lymphoedema advises that on initial assessment the treatment and management plan is differentiated into two pathways depending on the severity of the oedema [Additional file 1]. For patients with mild/moderate oedema a programme which encourages self-management at home is taught at the initial appointment; this involves skin care, exercise, compression/taping and simple lymphatic drainage (SLD). For more severe oedema, manual lymphatic drainage (MLD) is offered as a course over several appointments.

- MLD - The roots of MLD may be credited partly to Danish massage therapist Emil Vodder who developed the techniques for chronic sinusitis in the 1930s [13, 14]. It was first used for the treatment of lymphoedema by Vodder in 1965 [15]. There are now several schools of MLD based on the principles of the Vodder techniques with recent knowledge of the mechanism of the lymphatic system producing an alternative form of MLD known as fluoroscopy guided MLD (FG-MLD or 'fill and flush' technique). The hand movements of FG-MLD on the skin assist in the movement of interstitial fluid through the tissue and the filling of the superficial lymphatics [16]. A deep oscillating machine can also be used to enhance the effect of the massage. Deep oscillating therapy works by using low frequency, electrostatic impulses which produces a tissue-relaxing and moderate vasoconstriction effect, which favours reabsorption of localised oedema and reduced fibrosis $[17,18]$. This is particularly useful in areas harder to massage such as the head and neck.

Although the hospice protocol for mild/moderate oedema does not indicate that MLD is an element necessary for successful treatment, it is often used when the patient experiences substantial symptoms of psychological distress resulting in poor quality of life [5]. Nixon et al. found that having time with a health care professional during treatment for head and neck lymphoedema was reassuring and aided adjustment to a new normal following treatment [8].

- SLD - This is a simplified version of MLD which patients can be taught for self-management at home. Traditionally, it is recommended that the swollen area itself is not massaged during SLD, as only a trained lymphoedema practitioner may be able to exert the correct pressure to encourage movement of the lymph fluid [19]. However, SLD is now rarely used in the traditional manner [20], and head and neck cancer patients can be taught to massage the oedematous area often with good effect.

- Compression - This is traditionally one of the corner stones of treatment for lymphoedema [20]. Although compression garments are often thought not to be as useful in head and neck oedema as they are for oedema of a limb [6] the hospice clinic has found that wearing adapted compression is tolerated well and many patients find it a useful addition in the management of the condition.

- Elastic therapeutic tape (kinesiology tape) - This may be used in areas of the body where it is difficult to apply compression hosiery or bandages. Care needs to be taken as the skin is vulnerable to tissue damage. Cancer patients using elastic therapeutic tape may have less pronounced symptoms of lymphoedema, although it must be used with caution [21].

- Skin care - It is important that the healthcare professional encourages the patient to examine and care for their skin daily [22]. Skin care maintains 
skin integrity and helps prevent infection; it is extremely important as part of a treatment plan for all patients with lymphoedema [23, 24].

The Glasgow Benefit Inventory is a validated postinterventional questionnaire applicable to otorhinolaryngology procedures which measures changes in health status. It was first described by Robinson et al. in 1996 and consists of a questionnaire of 18 questions each based on a five-point Likert scale (scored one to five) [25]. The 18 questions address health related aspects of general, social and physical health. The Glasgow Benefit Inventory scores range from -100 to +100 , with a score of zero indicating no benefit and a score of +100 indicating maximum benefit.

The aim of this study was to quantify the health benefits of lymphoedema treatment using the Glasgow Inventory Benefit questionnaire, in patients with a history of treated head and neck cancer.

\section{Methods}

This was a prospective study where patients were recruited from the head and neck oncology follow-up clinic. Any patient who had undergone treatment with curative intent of a primary head and neck malignancy who had been referred for lymphoedema treatment was eligible for inclusion. Patients were referred for lymphoedema treatment at one of their routine follow-up appointments if it was felt by the clinician and patient together during the consultation that the intervention may be helpful.

The lymphoedema treatment plan for each patient was devised as per our hospice lymphoedema service protocol [Additional file 1] depending on the severity of the oedema [9-11]. For mild/moderate oedema, the first appointment typically involved information provision, skin care advice, exercises, compression and SLD. A second visit at 4 weeks was offered to revisit skin care and SLD. A compression garment or tape was provided if necessary. A third visit after a further 3 months was offered if the patient was not self-managing their oedema, with further appointments every 6 months with the aim to discharge after 2 years. For patients with more severe oedema, or those with mild/moderate oedema but substantial symptoms of psychological distress resulting in poor quality of life, the treatment plan was altered to include a course of MLD over four to six visits.

All patients who returned for a subsequent follow-up appointment in the head \& neck clinic after receiving the course of lymphoedema treatment were invited to take part in the study and provided with a questionnaire to complete at the end of the clinic consultation. Patients were recruited between September 2018 and February 2019 (inclusive). Completion of the questionnaire was optional and did not change any subsequent clinical care that they received. Furthermore, referral for lymphoedema treatment was not made on the basis that the patient would subsequently take part in a questionnaire after the intervention.

The total score from all 18 questions on the Glasgow Benefit Inventory questionnaire was calculated and then averaged to give equal weight to each question. Three (i.e. the score associated with no change) was subtracted from the total and the result multiplied by 50 to produce a benefit score for the patient ranging from -100 to + 100. Scores for three subscales were also calculated as follows: 12 questions relating to general factors, three questions relating to social support issues, and three questions concerning physical health.

\section{Results}

A total of 15 patients, aged between 51 to 78 years, with a mean age of 64 years, completed the post intervention questionnaire. The patient demographics are displayed in Table 1. One patient did not complete the questionnaire completely and did not provide answers to calculate the physical benefit and social benefits subscales.

Thirteen (87\%) of patients were assessed as having mild submental oedema while the remaining two (13\%) had moderate oedema.

All 15 (100\%) patients were given skin care advice as part of the self-management plan and all were offered compression. Half of the patients (50\%) wore the compression garment regularly, particularly during the evening when at home. All patients were taught how to carry out daily SLD. Two (13\%) patients were aided by a partner to perform this. Five (33\%) patients received FGMLD and four (27\%) were taught how to apply elastic therapeutic tape to the submental region.

Ten patients (67\%) demonstrated some level of improvement in quality of life with the total score for the Glasgow Benefit Inventory (Table 2, Fig. 1), while two (13\%) patients reported no benefit and three (20\%) reported negative improvements. The average score for the total Glasgow Benefit Inventory scale was +7.2 . The greatest benefit was demonstrated with the physical benefit subscale, where the average score was +13.1 . The average general benefit score was +9.0.

\section{Discussion}

Lymphoedema is a potentially common effect after treatment for head and neck cancer, where surgery and/or radiotherapy can disrupt the normal lymphatic flow. The incidence can vary between 12 and 54\% yet the condition remains under-recognised and under-treated [26]. It can be associated with functional deterioration and poor quality of life [5, 27]. Clinical interest in lymphoedema in head and neck cancer has increased in the last decade 
Table 1 Patient demographics and lymphoedema treatment provided

\begin{tabular}{|c|c|}
\hline Characteristic & Patients (n (\%)) \\
\hline \multicolumn{2}{|l|}{ Sex } \\
\hline Male & $12(80)$ \\
\hline Female & $3(20)$ \\
\hline \multicolumn{2}{|l|}{ Site of pathology } \\
\hline Oropharynx & $10(67)$ \\
\hline Unknown primary & $2(13)$ \\
\hline Hypopharynx & $1(7)$ \\
\hline Larynx & $1(7)$ \\
\hline Submandibular gland & $1(7)$ \\
\hline \multicolumn{2}{|l|}{ Cancer treatment } \\
\hline Chemoradiotherapy & $5(33)$ \\
\hline Chemoradiotherapy \& surgery & $4(27)$ \\
\hline Radiotherapy & $3(20)$ \\
\hline Radiotherapy \& surgery & $3(20)$ \\
\hline \multicolumn{2}{|l|}{ Disease status during lymphoedema treatment } \\
\hline Disease free & $14(93)$ \\
\hline Active disease & $1(7)$ \\
\hline \multicolumn{2}{|l|}{ Site of oedema } \\
\hline Submental & $14(93)$ \\
\hline Submental \& cheek & $1(7)$ \\
\hline \multicolumn{2}{|l|}{ Severity of oedema } \\
\hline Mild & $13(87)$ \\
\hline Moderate & $2(13)$ \\
\hline \multicolumn{2}{|l|}{ Treatment provided } \\
\hline Skin care & $15(100)$ \\
\hline Exercise & $15(100)$ \\
\hline Compression & $15(100)$ \\
\hline Simple lymphatic drainage & $13(87)$ \\
\hline Simple lymphatic drainage by carer & $2(13)$ \\
\hline Manual lymphatic drainage with oscillator & $5(33)$ \\
\hline Elastic therapeutic tape & $4(27)$ \\
\hline Literature & $15(100)$ \\
\hline
\end{tabular}

and recent reviews have attempted to examine the evidence and management of the condition, but there is still limited information about the evaluation and effectiveness of treatments $[26,28]$.

Lymphoedema associated with head and neck cancer appears to be a distinct entity from lymphoedema in other sites and therefore requires a specific regimen of therapy particularly targeted towards head and neck patients [29]. Possible treatments may include physiotherapy, or a form of MLD. This can be combined with other modalities including tissue compression, remedial exercises and skin care [29]. MLD is relatively straightforward to teach and is not associated with any significant side effects. Other treatments may involve selenium, liposuction and lymphaticovenular anastomosis and while there are some studies suggesting these treatments are effective in a small number of patients, there are limited large randomised controlled trials [28].

A recent systematic review evaluated all established treatment modalities for lymphoedema associated with head and neck cancer [28]. Twenty-six articles were included in the review, totalling 1018 study subjects. The review concluded that there was limited evidence for the efficacy for all types of lymphoedema therapy. MLD was the most studied therapy, although liposuction and surgical treatments may also be effective in some patients.

There is no standardised way to grade the severity of lymphoedema or to quantify improvement after treatment. One group in the USA describe a number of different measurements to create a neck and facial composite score and lymphoedema rating scale which can be used to measure the degree of lymphoedema [29]. In this study, we describe using the Glasgow Benefit Inventory, a validated post-interventional questionnaire, to measure patient reported outcomes in relation to health status after treatment for lymphoedema. The Glasgow Benefit Inventory has become popular to use as a generic patientrecorded outcome measure in outcomes after intervention in otorhinolaryngology conditions.

In this current study, the average total Glasgow Benefit Inventory was positive $(+7.2)$ suggesting an improvement in quality of life following lymphoedema treatment as reported by the patients. The general benefit $(+9.0)$ and physical benefit $(+13.1)$ subscales also demonstrated positive average scores. A recent review examined the reporting of Glasgow Benefit Inventory outcomes for different interventions and objectives [30]. The average levels of improvement reported in other studies is higher than in the current study, but this may reflect a discrete one-off intervention (for example cochlear implant) rather than a longer treatment regimen which requires ongoing compliance from the patient.

Unfortunately, not every patient reported improvement in their symptoms and indeed the social benefit subscale was negative. However, this does parallel other studies. In one large study of 1202 patients, 733 were evaluated for response to lymphoedema therapy and while $60 \%$ did show improvement in their symptoms after treatment, $40 \%$ did not [29].

The intervention described in this study involved patient education to teach self-care activities to help improve lymphoedema. Patients have previously expressed positive comments about lymphoedema self-care yet this requires patients to be motivated and compliant [31]. Those who are compliant with recommended treatment 
Table 2 Outcomes from lymphoedema treatment using the Glasgow Benefit Inventory scores

\begin{tabular}{|c|c|c|c|c|}
\hline Patient & $\begin{array}{l}\text { Glasgow Benefit } \\
\text { Inventory total score }\end{array}$ & $\begin{array}{l}\text { Glasgow Benefit Inventory } \\
\text { general benefit score }\end{array}$ & $\begin{array}{l}\text { Glasgow Benefit Inventory } \\
\text { physical benefit score }\end{array}$ & $\begin{array}{l}\text { Glasgow Benefit Inventory } \\
\text { social benefit score }\end{array}$ \\
\hline Patient 1 & -50.0 & -41.7 & -50.0 & -83.3 \\
\hline Patient 2 & -19.4 & -16.7 & -16.7 & -33.3 \\
\hline Patient 3 & 0.0 & 0.0 & 0.0 & 0.0 \\
\hline Patient 4 & +5.6 & +4.2 & 0.0 & +16.7 \\
\hline Patient 5 & 0.0 & 0.0 & 0.0 & 0.0 \\
\hline Patient 6 & +16.7 & +12.5 & +33.3 & +16.7 \\
\hline Patient 7 & +13.9 & +12.5 & +50.0 & -16.7 \\
\hline Patient 8 & -2.8 & 0.0 & +16.7 & -33.3 \\
\hline Patient 9 & +11.1 & +20.8 & +16.7 & -33.3 \\
\hline $\begin{array}{l}\text { Patient } \\
10\end{array}$ & +8.3 & +12.5 & 0.0 & 0.0 \\
\hline $\begin{array}{l}\text { Patient } \\
11\end{array}$ & +16.7 & +20.8 & +83.3 & -66.7 \\
\hline $\begin{array}{l}\text { Patient } \\
12\end{array}$ & +25.0 & +25.0 & +16.7 & +33.3 \\
\hline $\begin{array}{l}\text { Patient } \\
13\end{array}$ & +13.9 & +16.7 & 0.0 & +16.7 \\
\hline $\begin{array}{l}\text { Patient } \\
14\end{array}$ & +30.6 & +29.2 & +33.3 & +33.3 \\
\hline $\begin{array}{l}\text { Patient } \\
15^{\mathrm{a}}\end{array}$ & +38.9 & +38.9 & - & - \\
\hline Average & +7.2 & +9.0 & +13.1 & -10.7 \\
\hline
\end{tabular}

${ }^{a}$ This patient did not complete the questionnaire completely and has been excluded from calculation of the physical benefit and social benefit subscale scores

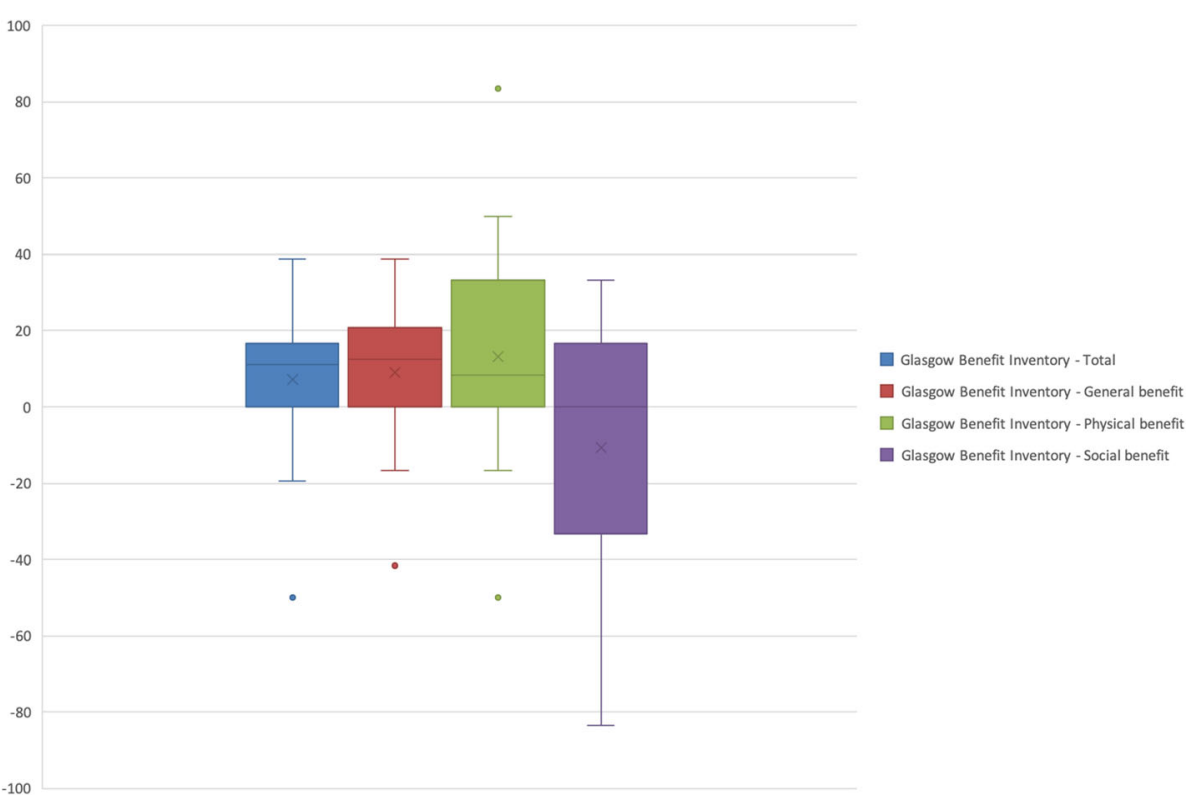

Fig. 1 Box and whisker plot demonstrating total and subscale scores for Glasgow Benefit Inventory 
regimens have significantly better rates of improvement than those who are non-compliant [4]. However, even in those patients who are only partially compliant with treatment there may still be a demonstrable improvement in their symptoms [29]. Since the technique can fairly easily be taught to patients and most can complete the exercises at home without side effects or complications, it is something which should be offered to patients as they may derive some benefit from the treatment if they are motivated.

\section{Conclusions}

Lymphoedema is a common side effect after treatment for head and neck cancer. Treatment may involve various forms of compression, exercise, skin care and lymphatic massage which can be coordinated by a qualified lymphoedema practitioner. In this study, there were mild improvements in patient reported quality of life using the Glasgow Benefit Inventory in the majority of patients. Patient self-care is an important aspect of lymphoedema treatment but requires patient motivation. Lymphoedema associated with head and neck cancer is likely a distinct entity from lymphoedema in other sites and while clinical interest in the condition has increased recently, there is still limited information about the effectiveness of treatments and future research should look to address these issues.

\section{Supplementary information}

Supplementary information accompanies this paper at https://doi.org/10. 1186/s41241-020-00093-y.

Additional file 1.

\section{Abbreviations}

FG-MLD: Fluoroscopy guided manual lymphatic drainage; MLD: Manual lymphatic drainage; SLD: Simple lymphatic drainage

\section{Acknowledgements}

The authors wish to acknowledge the head \& neck cancer nurse specialists (Amanda Davies, Gina McRobb and Amanda Morris) for their help in collecting the patient data.

\section{Authors' contributions}

All authors contributed to the study conception and design. Material preparation, data collection and analysis were performed by EH and SFA. The first draft of the manuscript was written by $\mathrm{EH}$ with significant contributions from JG. All authors commented on previous versions of the manuscript. All authors read and approved the final manuscript.

\section{Funding}

This research did not receive any specific grant from funding agencies in the public, commercial, or not-for-profit sectors.

\section{Availability of data and materials}

The data used as part of this current study are available from the corresponding author on reasonable request.

\section{Ethics approval and consent to participate}

Ethical approval was not required for this questionnaire as it was completed after treatment and did not affect the care received by any of the patients.
Nevertheless, the questionnaire was provided to participants in accordance with the ethical standards of our institution and with the 1964 Helsinki declaration and its later amendments.

\section{Consent for publication}

Not applicable.

\section{Competing interests}

The authors declare that they have no competing interests.

\section{Author details}

${ }^{1}$ Department of ENT, Shrewsbury and Telford Hospital NHS Trust, Royal Shrewsbury Hospital, Mytton Oak Road, Shrewsbury SY3 8XQ, UK. ${ }^{2}$ Therapy Department, Severn Hospice, Apley Castle, Apley, Telford TF1 6RH, UK.

Received: 17 February 2020 Accepted: 7 October 2020

Published online: 19 October 2020

\section{References}

1. Büntzel J, Glatzel M, Mücke R, Micke O, Bruns F. Influence of amifostine on late radiation-toxicity in head and neck cancer--a follow-up study. Anticancer Res. 2007:27:1953-6.

2. Deng J, Ridner SH, Dietrich MS, Wells N, Wallston KA, Sinard RJ, Cmelak AJ, Murphy BA. Prevalence of secondary lymphedema in patients with head and neck cancer. J Pain Symptom Manag. 2012;43:244-52.

3. Deng J, Ridner SH, Dietrich MS, Wells N, Wallston KA, Sinard RJ, Cmelak AJ, Murphy BA. Factors associated with external and internal lymphedema in patients with head-and-neck cancer. Int J Radiat Oncol Biol Phys. 2012;84. e319-28.

4. Smith BG, Lewin JS. The role of lymphedema Management in Head and Neck Cancer. Curr Opin Otolaryngol Head Neck Surg. 2010;18:153-8.

5. Deng J, Murphy BA, Dietrich MS, Wells N, Wallston KA, Sinard RJ, Cmelak AJ, Gilbert J, Ridner SH. Impact of secondary lymphedema after head and neck cancer treatment on symptoms, functional status, and quality of life. Head Neck. 2013;35:1026-35.

6. McGarvey AC, Osmotherly PG, Hoffman GR, Chiarelli PE. Lymphoedema following treatment for head and neck cancer: impact on patients, and beliefs of health professionals. Eur J Cancer Care (Engl). 2014;23:317-27.

7. Deng J, Murphy BA, Dietrich MS, Sinard RJ, Mannion K, Ridner SH. Differences of symptoms in head and neck cancer patients with and without lymphedema. Support Care Cancer. 2016;24:1305-16.

8. Nixon JL, Pigott AE, Cartmill B, Turner J, Fleming J, Porceddu SV. A mixed methods examination of distress and person-centred experience of head and neck lymphoedema. Oral Oncol. 2018;83:18-24.

9. Jeffs E, Huit M. Treatment and outcomes of head and neck oedema referrals to a hospital-based lymphoedema service. Br J Community Nurs. 2015; 20(Suppl 4):S6-13. https://pubmed.ncbi.nlm.nih.gov/25950400/.

10. Földi M, Földi E. Földi's textbook of Lymphology. 3rd ed. Elsevier Urban \& Fischer: Munich; 2012.

11. International Lymphoedema Framework. Best practice for the Management of Lymphoedema. London: Medical Education Partnership (MEP) Ltd; 2006.

12. Brown A. Encouraging self-management of simple lower limb lymphoedema. Nurse Prescribing. 2018;16:S4-S10.

13. Kasseroller RG. The Vodder school: the Vodder method. Cancer. 1998;83: 2840-2.

14. Chikly BJ. Manual techniques addressing the lymphatic system: origins and development. J Am Osteopath Assoc. 2005;105:457-64.

15. Vodder E. Vodder's lymph drainage. A new type of chirotherapy for esthetic prophylactic and curative purposes [article in German]. Asthet Med (Berl). 1965;14:190-1.

16. Wigg J, Cooper-Stanton G. How is lymphofluoroscopy mapping altering lymphoedema management? Br J Community Nurs. 2017;22:S16-20.

17. Hernandez S, Fernández M, Iturralde $Y$, Fernández A. The effect of deep oscillation therapy in fibrocystic breast disease. A randomized controlled clinical trial. Int Arch Med. 2018;11:1-10.

18. Jones J. Case study: use of oscillation therapy and MLLB in cancer-related oedema. Br J Community Nurs. 2012;17:S17-21.

19. Macmillan Cancer Support. Understanding Iymphoedema. 15th ed. London: Macmillan Cancer Support; 2018.

20. Wigg J, Lee N. Redefining essential care in lymphoedema. $\mathrm{Br} J$ Community Nurs. 2014;19(Suppl4):S20-7.https://pubmed.ncbi.nlm.nih.gov/24704751/. 
21. Gatt M, Willis S, Leuschner S. A meta-analysis of the effectiveness and safety of kinesiology taping in the management of cancer-related lymphoedema. Eur J Cancer Care (Engl). 2017;26:e12510.

22. Elwell R, Craven N. A glossary of terms to assist the recognition and diagnosis of skin conditions associated with lower-limb chronic oedema. $\mathrm{Br}$ J Community Nurs. 2015;20:S14-20.

23. Committee E. The diagnosis and treatment of peripheral lymphedema: 2016 consensus document of the International Society of Lymphology. Lymphology. 2016;49:170-84

24. Nowicki J, Siviour A. Best practice skin care management in lymphoedema. Wound Pract Res. 2013;21:61-5.

25. Robinson K, Gatehouse S, Browning GG. Measuring patient benefit from otorhmolaryngological surgery and therapy. Ann Otol Rhinol Laryngol. 1996; 105:415-22.

26. Anand A, Balasubramanian D, Subramanian N, Murthy S, Limbachiya S, lye S, Thankappan K, Sharma M. Secondary lymphedema after head and neck cancer therapy: a review. Lymphology. 2018;51:109-18,

27. Murphy BA, Gilbert J, Cmelak A, Ridner SH. Symptom control issues and supportive care of patients with head and neck cancers. Clin Adv Hematol Oncol. 2007;5:807-22.

28. Tyker A, Franco J, Massa ST, Desai SC, Walen SG. Treatment for lymphedema following head and neck cancer therapy: a systematic review. Am J Otolaryngol. 2019;40:761-9.

29. Smith BG, Hutcheson KA, Little LG, Skoracki RJ, Rosenthal DI, Lai SY, Lewin JS. Lymphedema outcomes in patients with head and neck cancer. Otolaryngol Head Neck Surg. 2015;152:284-91.

30. Hendry J, Chin A, Swan IR, Akeroyd MA, Browning GG. The Glasgow benefit inventory: a systematic review of the use and value of an otorhinolaryngological generic patient-recorded outcome measure. Clin Otolaryngol. 2016;41:259-75.

31. Deng J, Murphy BA. Lymphedema self-care in patients with head and neck cancer: a qualitative study. Support Care Cancer. 2016;24:4961-70.

\section{Publisher's Note}

Springer Nature remains neutral with regard to jurisdictional claims in published maps and institutional affiliations.

Ready to submit your research? Choose BMC and benefit from:

- fast, convenient online submission

- thorough peer review by experienced researchers in your field

- rapid publication on acceptance

- support for research data, including large and complex data types

- gold Open Access which fosters wider collaboration and increased citations

- maximum visibility for your research: over $100 \mathrm{M}$ website views per year

At $\mathrm{BMC}$, research is always in progress.

Learn more biomedcentral.com/submissions 